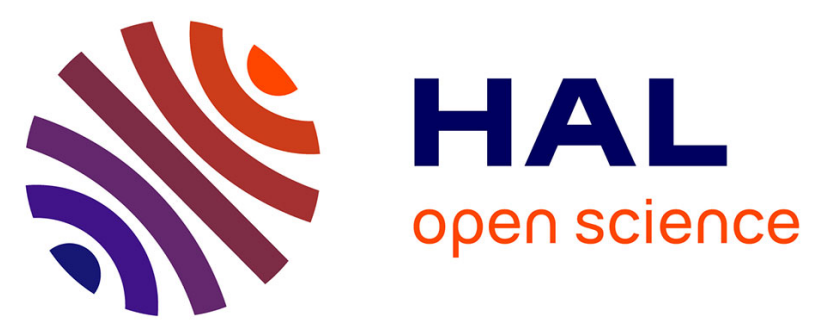

\title{
Using the Product Lifecycle Management Systems to Improve Maintenance, Repair and Overhaul Practices: The Case of Aeronautical Industry
}

Alejandro Romero, Darli Rodrigues Vieira

\section{- To cite this version:}

Alejandro Romero, Darli Rodrigues Vieira. Using the Product Lifecycle Management Systems to Improve Maintenance, Repair and Overhaul Practices: The Case of Aeronautical Industry. 11th IFIP International Conference on Product Lifecycle Management (PLM), Jul 2014, Yokohama, Japan. pp.159-168, 10.1007/978-3-662-45937-9_17 . hal-01386492

\section{HAL Id: hal-01386492 \\ https://hal.inria.fr/hal-01386492}

Submitted on 24 Oct 2016

HAL is a multi-disciplinary open access archive for the deposit and dissemination of scientific research documents, whether they are published or not. The documents may come from teaching and research institutions in France or abroad, or from public or private research centers.
L'archive ouverte pluridisciplinaire HAL, est destinée au dépôt et à la diffusion de documents scientifiques de niveau recherche, publiés ou non, émanant des établissements d'enseignement et de recherche français ou étrangers, des laboratoires publics ou privés.

\section{(c)(1)}

Distributed under a Creative Commons Attribution| 4.0 International License 


\title{
Using the Product Lifecycle Management Sys- tems to Improve Maintenance, Repair and Overhaul Practices: the Case of Aeronautical industry
}

\author{
Alejandro Romero ${ }^{1}$ and Darli Rodrigues Vieira ${ }^{2}$ \\ ${ }^{1}$ Université du Québec à Montréal (UQAM), Management Project Chair, Canada, romero- \\ torres.alejandro@uqam.ca \\ ${ }^{2}$ Université du Québec à Trois-Rivières (UQTR), Research Chair in Management of \\ Aeronautical projects ,Canada, darli.vieira@uqtr.ca
}

\begin{abstract}
Airlines companies trust in MRO facilities for extending lifespan of their assets to ensure the availability of transportation services. Nevertheless, MRO services are complex because they involve several processes whose performance depends on the design and manufacturing of products while airlines require the best-cost efficiency, quality and safety. Product lifecycle management (PLM) could improve the productivity and quality of MRO since it enables the collaborative creation, management, dissemination, use, maintenance and repair of products and its operational process information across the entire life of products from market concept to product retirement. However, it seems that PLM and MRO relationship in the aeronautical industry has been studied very sparsely in the literature. This paper attempts to gain a better understanding of the influence of product life management system in MRO services. The objectives of this study are twofold: 1) to identify MRO provider's requirements concerning PLM systems, and 2) to assess how PLM system could be improved to better support MRO services.
\end{abstract}

Keywords: Maintenance, repair, overhaul, aeronautical, product lifecycle management.

\section{Introduction}

The aeronautical sector including aircraft construction, aircraft parts supply or maintenance, repair and overhaul (MRO) service is today one of the most dynamic industries in the world. This industry creates enormous amounts of economic activity and fiscal benefits for several countries. AeroStrategy assessed that the global aerospace industry will be worth 1,200 billion dollars by 2014 [1]. Specifically, the defense sector will represent $71.8 \%$ of the market while the commercial aviation will contribute the remaining $28.2 \%$ [2]. The aerospace industry is closely linked to the continuous innovation and development of new technologies, new materials and new procedures, contributing in a significant manner to the economic and social development of countries.

The actual number of aircrafts in the air and the significant increase of new production, order backlog for Airbus and Boeing was approximately 9055 aircrafts in 
2012 (Flight Global, 2013), have increased the importance of MRO services in this industry. For instance, U.S. airlines operate a mixed fleet of aircraft comprised of primarily older planes (60\% of their inventory). It was estimated that a large percentage of these old aircraft will be due for heavy checks or overhauls [4]. The increase in capacity of commercial and military sector, along with greater aircraft utilization, will lead to increased maintenance and safety demands, creating new challenges for the MRO industry [5]. In fact, MRO providers create the capability to support the functioning of the aeronautical machines, extending their lifespan and ensuring transportation services.

MRO services are complex since they involve several processes whose performance depends on the design and manufacturing of products while airlines require the best-cost efficiency, quality and safety. MRO entities ensure the maintenance of a variety of aircraft systems, components and parts, which requires investments in infrastructure, compliance with government regulations and updating of technical staff. Product lifecycle management (PLM) could improve the productivity and quality of MRO. Indeed, it enables the collaborative creation, management, dissemination, use, maintenance and repair of products and its operational process information across the entire life of products from market concept to product retirement. However, it seems that PLM and MRO has not been studied sufficiently in the literature [6]. Therefore, this paper attempts to gain a better understanding of the influence of maintenance repair and overhaul requirements on the product life management strategies in the aeronautical industry.

The objectives of this paper are twofold: 1) to identify MRO provider's requirements concerning PLM systems, and 2) to assess how PLM system could be improved to better support MRO services. The paper is structured as follows. The next section briefly presents a review of the literature. The third section outlines the methodological strategy. The fourth one examines the main PLM strategies to strengthen MRO services. The paper concludes with a discussion on the suitability of PLM in MRO.

\section{Literature review}

\subsection{Aeronautical industry}

The aerospace industry can be divided into two large sectors delimited by the operating range of products. The aeronautics sector is responsible for aircrafts operating within the earth's atmosphere and the astronautics is for products that may operate outside the atmosphere [7]. MRO services are necessary in both sectors, but MRO providers for aeronautical product are not equipped to provide the same service for astronautics products. Aeronautical sector include both military and commercial aircrafts [7]. All these sub-sectors share similar functional structure but focus on different markets and products (see figure 1). 


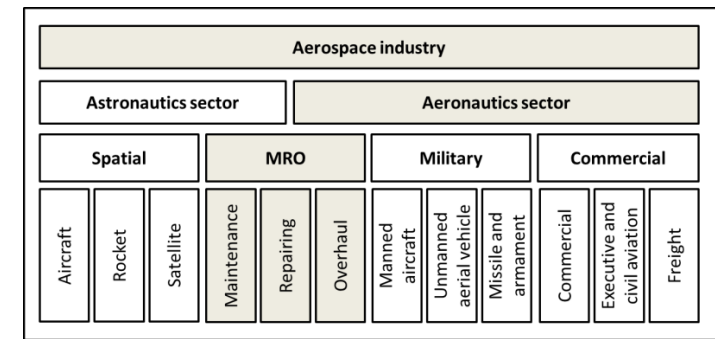

Fig. 1 Aerospatiale industry structure (based on [2])

Some products use the same technological platform irrespective of whether they were developed for military purposes or for commercial transport of passengers and freight [8]. Nevertheless, most aircrafts require special procurement procedures, certifications and specific technological features [9]. For instance, the interiors of the executive and civil aircraft have a high degree of customization and advanced materials, which will be used later in commercial aviation.

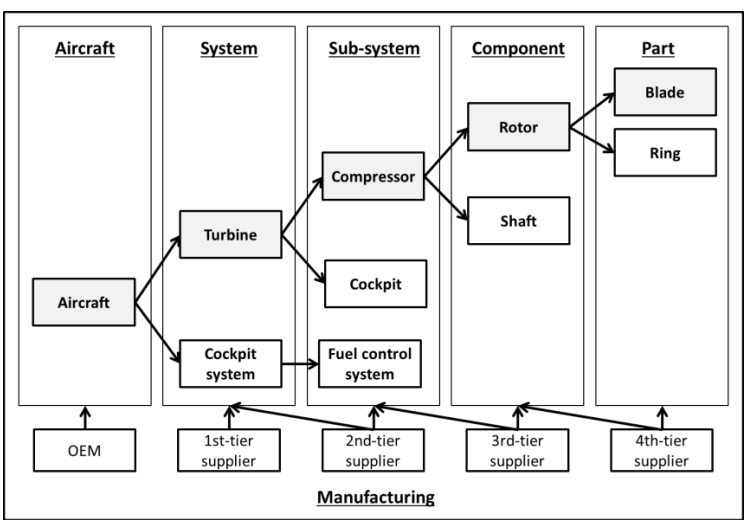

Fig. 2 Aircraft product and manufacturing structure (based on [10])

The structure of the commercial aviation industry is frequently compared to the automobile industry; however there are substantial differences in the level of demand certifications and standards, quality, safety, security, time to market, volume parts and life of the cycle product [11]. To better understand the differences between both industries, it's crucial to describe how aircraft products are structured. The largest unit is the aircraft, which is defined as a complete and operational unit. The aircraft is segmented into systems, covering key functions of the aircraft such as the turbine whose function is to provide the power for the lifting of the craft in the air [10]. Further, systems can contain subsystems or components depending upon their complexity. In the above example, a subsystem of the turbine is the compressor which has the function of compressing the air prior to mixing it with the fuel in the combustion chamber [10]. The turbine has several components such as the rotor and shaft. The rotor compresses the air to gradually reduce its size and the shaft spins the rotor [10]. Finally, these components are composed of several parts such as rotor blades (see figure 2). 


\subsection{Maintenance, repair and overhaul (MRO)}

MRO is the set of activities designed to allow aircrafts to operate safety, efficiently and respecting aviation regulations. MRO services involve the repair of any mechanical, electrical, electronic, hydraulic component (unscheduled maintenance, faults detection and repairs). They also include the execution of routine activities that keep the components in working condition (scheduled maintenance) or that simply prevent failures (preventive maintenance). For the aeronautical industry, MRO is the basis for adding value to the products' performance.

MRO services worldwide reach a value of $\$ 149.2$ billion by 2013 and are equivalent to $35 \%$ of sales in the aeronautical sector [12]. Military sector represents $70 \%$ of the total market while the commercial aviation contributes the remaining $30 \%$ [13]. For instance, commercial companies spent $35 \%$ of their MRO budget on turbine maintenance, $23 \%$ on subsystems and components maintenance, $20 \%$ on line maintenance, $15 \%$ on aero-structures repair and $7 \%$ on modifications [13]. The global MRO market has 300-400 suppliers, located in all continents. It is estimated that the global market for MRO services will have long-term growth rate of 3.3\%, representing by 2019 a total expenditure of $\$ 183$ billion dollars [14]. MRO service will be the fastest growing segment of the aerospace industry.

MRO facilities principally offer three services: maintenance, repair and overhaul. Maintenance corresponds to the review, cleaning, lubrication and replacement of minor parts of the aircraft. It's often programmed to be undertaken after a certain amount flight hours (every day for line maintenance or every month for minor maintenance) [15]. Repair refers to the mechanical reprocess for serious failures discovered during maintenance. Finally, overhaul corresponds to the complete review of the aircraft which is executed when aircraft has completed 4000 and 5000 flight hours. The objective is to check thoroughly every system, component and tool of the aircraft and meet the condition standards of quality required for all the components. Overhaul also includes the incorporation of new technologies or systems [16].

MRO providers offer different type of check services, namely A, B, C and D $[17,18]$. An " $A$ " check is performed approximately every $500-800$ flight hours. It is usually done overnight at the airport. The recurrence of this service varies by aircraft type, the cycle count (one cycle consists of one takeoff and one landing), or the number of hours in air since last service. A " $\mathrm{B}$ " check is executed approximately every 3 or 6 months. It usually lasts for 1 to 3 days in a hangar. "B" check recurrence depends on the same factors as that of an "A" check. A " $C$ " check happens approximately every 15 to 21 months or a certain number of flying hours. This service is more extensive than a " $\mathrm{B}$ " check. Almost the entire aircraft is inspected keeping it out of service until this check is completed at the maintenance site. The space required for the execution of the service is also higher. It requires the hangar and a maintenance base equipped with set of workshops. The average completion time is usually 1-2 weeks. Recurrence depends on flying hours, but specifically on the manufacturer's recommendations. A "D" check, also known as Heavy Maintenance Visit (HMV), is the most demanding of MRO services. This 
check is performed approximately every 5 or 6 years. Almost all the aircraft is disarmed for inspection and repair purposes. It can last for 3 weeks to 2 months depending on the service provider, its resources, and the general condition of the aircraft. A Boeing 747 for instance requires the participation of 100 technicians for executing a " $\mathrm{D}$ " check to the aircraft parts, executing tests and ensuring the necessary installations [16].

\subsection{Product lifecycle management (PLM) for MRO services}

In the aeronautical industry, PLM aims principally to manage the aircraftproduct definition with respect to the functioning of its relative subsystems (see figure 2), from their conception to their final disposal. PLM systems by inclusion of functionalities such as requirement management, data management, digital visualization and configuration management, allow for sharing product information throughout the product value chain. Furthermore, PLM allows for synchronizing nomenclatures resulting from different lifecycle phases namely design, manufacture, assembly and service.

Technology advancements could bring important benefits to improve MRO services. For instance, MRO facilities are looking for ways to streamline their maintenance operations through automation by way of informational technology. Advances in computer technology especially in the area of information technology have made the MRO procedures highly technical [19]. They can benefit from pervasive advantages of technology such as electronic manuals and electronic information which eliminates the need to deal with high volumes of paper to obtain needed maintenance information

Adopted years ago by different industries, PLM system could bring information about the aircraft components and pieces to the actors participating in the lifecycle of aircrafts. PLM systems are developed and adopted to gather all the relevant information that affects a product throughout its life, from concept through retirement (including its maintenance and repair) and managing the communication of that information to facilitate product and process improvement [20]. PLM capture principally information of the activities conducted during design engineering such as computer-aided design applications, 3D modeling and simulation or Bill of Material [21]. Specification data regarding component parts, materials, tools and other attributes is defined in these systems. Information improving MRO services are also integrated into PLM platforms such as process flows, work instructions and inspection criteria [17]. The resulting documentation contains every detail about the product and process definition.

The benefits of extending PLM to production can be realized quickly with manufacturing operations software tightly integrated to a manufacturer's PLM system, such as enterprise resource planning (ERP) customer relationship management, management of supply chain (SCM) and design applications (CAD) [21]. Supported by PLM, Aircraft manufacturers could improve their ability to enforce as-planned execution results with fewer mistakes, integrate engineering 
data facilitating faster decision making and communicate manufacturing data to engineering and providers [20, 22].

However, data contained in PLM applications often does not encompass the complete lifecycle of the product. Several authors in the literature stated that PLM improves the collaboration from design to manufacturing procedures but it must extend their benefits to the MRO services and final disposal $[6,17]$. Further, PLM must capture and spread information into two directions: from supply chain upstream to downstream and vice versa. Lee et co-authors [6] studied the adoption of PLM tools by an MRO provider. They identified that PLM could establish a more comprehensive relation between customers, suppliers and business partners since MRO providers could get manufacturing information easily to provide the right MRO services. In turn, MRO facilities could register maintenance and repair information into PLM tools to share it to manufacturers and airlines for product improvement purpose [6]. Yu and Gulliver [17] conclude that PLM could provide accurate information to MRO providers to ensure quality and to reduce service cost.

\section{Methodology}

We executed an exploratory study based on a content analysis. Our goal is to answer to the following research questions: What are the main stakes for MRO providers? Which are the benefits of integrating PLM systems into MRO services? How do MRO providers use PLM systems? How could PLM systems be improved? The executed content analysis is based on public information about PLM uses and MRO requirements. We identified several documents such as research papers, academic documents, white papers, industrial documents and news. Data were coded and classified based on the current topics: such as needs of MRO providers for its functioning, benefits of PLM in aeronautical section, information required by MRO's and PLM implementation. Table 1 shows the distribution of information collected in function of the above classification. Based on these classifications, we analyzed MRO needs and PLM capacities for aeronautical industry to identify the main benefits of integrating PLM systems into MRO procedures. Some limitations were also identified by analyzing MRO information requirement and current PLM applications. No relevant information were found from available PLM implementations documents.

Table 1. Classifications of collected data

\begin{tabular}{lccccc|c}
\hline Type of documents & $\begin{array}{c}\text { Research } \\
\text { papers }\end{array}$ & $\begin{array}{c}\text { Academic } \\
\text { documents }\end{array}$ & $\begin{array}{c}\text { White } \\
\text { papers }\end{array}$ & $\begin{array}{c}\text { Industrial } \\
\text { documents }\end{array}$ & News & Total \\
\hline MRO needs & 2 & 2 & 3 & 5 & 10 & 22 \\
$\begin{array}{l}\text { Current PLM } \\
\text { benefits }\end{array}$ & 8 & 6 & 5 & 2 & 6 & 27 \\
$\begin{array}{l}\text { MRO information } \\
\text { requirements }\end{array}$ & 2 & 2 & 1 & 2 & 3 & 10 \\
$\begin{array}{l}\text { PLM implementa- } \\
\text { tion }\end{array}$ & 3 & 1 & 0 & 0 & 0 & 4 \\
\hline Total & 15 & 11 & 9 & 9 & 19 & 63 \\
\hline
\end{tabular}


Preliminary results were then validated by an expert on product lifecycle management in the aeronautical industry, by senior specialists from two aircraft manufacturing companies and by one senior specialist representing an MRO provider. Experts gave interesting insights that support research results.

\section{Preliminary results}

\subsection{PLM opportunities for MRO}

As shown in the literature and validated by the specialists, MRO services are complex for several reasons:

First, they must deal with a big variety of systems and sub-systems that have different maintenance procedures. Aircraft are sophisticated products since they are made up of thousands of components that come from a long supply chain and whose cycle life is measured in decades. To illustrate this, Airbus A300 was launched in 1969, he entered in service in 1974 and the last aircraft was delivered in July 2007. Apart from their long periods of production, aircrafts have long periods of use and consequently long periods of maintenance. For instance, the A380 underwent fatigue testing for 25 years of use. A quarter of the Airbus aircraft currently in service has exceeded its usage life of 20 years. These very long periods of service and production involve inevitably changes to the supply chain and changes to the system design. As mentioned by a specialist from an aircraft constructor, "during the prolonged life cycle of aircrafts, the customer requirements could evolve resulting in several product versions that differ from original design". PLM systems could capture this dynamic data and provide accurate information to MRO providers. In case of any version update, MRO provider could receive the instructions to upgrade systems and ensure that aircrafts in used respect requirements and specification of original manufacturers.

Second, MRO procedures depend deeply upon the production structure of aircrafts. Production comprises 5 levels (see figure 1): the first level is occupied by the main contractors, also called original equipment manufacturers (i.e. Airbus, Boeing, Embraer or Bombardier), that are responsible for designing and assembling aircrafts [23]. The first-tier supplier is in charge of assembling primary system and manufacture main components [24]. The second-tier supplier is responsible for sub-assembling primary systems and its components [24]. The third-tier supplier is in charge of manufacturing components. Finally, forth-tier supplier is responsible for producing simple components and parts [24]. For MRO services, providers must ensure the compatibility of their procedures with the recommendations provided by OEM manufactures, suppliers from all tiers, and airlines companies. They also require highly specialized aircraft expertise, a field that is constantly evolving and where specialties are changing over time. Following the above design-manufacturing structure, PLM systems could integrate the product information and the structure of their manufacturing. Indeed, OEM and systems providers integrate product information into a same platform for product assembly 
purposes. Using an effective PLM solution, MRO could get access to this integrated information and then communicate easily with the appropriate owner of products in case of any technical or specification problem.

Third, MRO demands are centered on safety and quality which are necessary to ensure airplanes are free from factors that may lead to injury or loss. Nevertheless, literature shows that MRO service could frequently fail. For instance, Aircraft maintenance and inspection errors have contributed to anywhere from 9 to 23 percent of airline accidents [25]. As described by a specialist participating in this study, the most common aviation maintenance problems include engine shutdowns, structural design problems, defective plane parts and flight employee negligence. Apart from high quality requirement, MRO solutions providers are also under pressure from commercial airlines for reducing costs. An estimated 20 to 30 percent of engine shutdowns are caused by maintenance errors, resulting in flight delays that could cost as much as $\$ 10,000$ per hour [26]. The increasing pressures to maintain a highly competitive advantage in the aviation industry have dramatically changed perceptions from tradition models of the past. Therefore, MRO provider could use a PLM system to share the information produced during maintenance and repair procedures. As in original production, material and process data will need to be collected to document MRO procedures. This electronic record ensures operations are approved in sequence; replacement materials meet specifications and tasks are performed by authorized MRO providers. In order to reduce time and cost of MRO services, several lean strategies are adopted such as $5 \mathrm{~S}$ process or Kaizen. PLM system could support the integration of these strategies. Indeed, it enables the identification of pieces using nomenclatures or codes. This identification system enables a better control of important volume of pieces. Therefore, MRO providers could decrease time spent on searching parts and finding their related information.

Finally, technology innovations not only bring opportunities to improve MRO services, they could increase the complexity of specifications and conditions for maintenance and repair. For instance, technological advancements in avionics systems require MRO providers to continuously provide up-to-date training to keep up with newer avionic platforms. Due to this increasing use of technology, more time is spent to repair aircraft systems. As mentioned by several specialists, sharing the same PLM solution with aircraft constructors and their suppliers could decrease the time to repair and improve knowledge. Extending PLM to maintenance can incorporate work instructions that are delivered in 3D just like during the manufacturing process. MRO workers could interact with the model to quickly and thoroughly understand the exact issue and solution. Original designs and historical maintenance data recorded in the as-built history can be viewed and compared.

\subsection{PLM limits for MRO}

Some of the participants of this study pointed to the actual limits of PLM solution that could explain why this system is not totally used by MRO providers. The first limit described is that actual PLM solutions meet the needs of engineers and only 
extend up to the point where a product is built. For MRO providers looking for knowledge of the life cycle beyond design through production of aircraft parts and subsystems, the information is limited and don't meet MRO needs. Specialists participating into this study stated that current systems don't encourage collaboration between engineering, manufacturing, the supply network and MRO service. Actually, they hinder continuous improvement efforts. Another specialist examining the MRO documents observed that the information available electronically is astronomical. He suggested a better aggregation of information to allow MRO providers to have all the information they need to complete a repair anywhere and anytime, from any location.

Apart from sharing information, MRO providers, airlines, OEM and systems providers must use PLM to improve their relative processes. Critical information is collected and could be used to better understand the procedures and need of aircraft lifecycle partners. OEM and aircraft system providers should focus on MRO stakes in order to improve the design of their products and, therefore, make easier their maintenance and repairing. For instance, they could identify that disassembly of systems is a complex process for MRO providers. Therefore, they could add as design requirement that aircraft systems could easily be disassembled. Some participants suggested that PLM system could enable this type of analyses to change design strategies to make it easier for MRO's to provide services.

\section{Conclusion}

PLM system allows MRO providers to decrease the complexity of their activities since it enables sharing and collecting information about aircraft systems. This information could be used to improve the control of all the aircraft components, to obtain a better knowledge of pieces requirements and updates but also it contribute to improve MRO quality and decrease time and cost. Beside these benefits, PLM systems are not completely used by MRO entities because they are not totally compatible with maintenance and repair processes and because the actual available information don't meet MRO requirement. It seems that even if PLM solutions become more sophisticated, aeronautical supply chain actors tend not to share their information. Improving PLM system to meet MRO needs could have several opportunities for MRO providers and commercial airlines. But, OEM and aircraft system providers could also get benefits. For instance, OEM could increase their revenues if they ensure that their products need less costly and timely MRO services [6]. To accomplish this objective, aircraft lifecycle actors must invest in improving their collaboration across their business wall. They should coordinate their efforts from design and manufacturing to MRO procedures. Indeed, PLM could make easier this task.

This paper presented an exploratory study that enables to have better understanding of the actual position of PLM in MRO services. This represents the first step for a grounded theory. Different data was collected from the content analysis and from specialist's validations and was coded into two main classifications: PLM benefits and limits. Further research will focus on analyzing how designers 
and manufacturers in aeronautical industry include into their activities the needs of their partners to improve the last phases of the product lifecycle, namely maintenance services provided by MRO's, recycling and final disposal.

\section{Acknowledge}

The authors would like to thank the two anonymous reviewers for their valuable and insightful comments and suggestions.

\section{References}

1. Deloitte, LLP Global Aerospace \& Defense Industry Financial Performance Study. http://www2.deloitte.com/content/dam/Deloitte/global/Documents/Manufacturing/gx AD indust ryperformancestudy_june2013.pdf (2013).

2. Aerostrategy. Aerospace Globalization 2.0: Implications for Canada's Aerospace Industry, Discussion paper. http://www.aiac.ca/uploadedFiles/Resources and Publications/Reference Documents/The\%20Implications\%20Of\%20Globalization\%202\%200\%20For\%20Canadian\%20Aeros pace(2).pdf (2009).

3. Flightglobal, Aircraft finance 2013, special report. www.flightglobal.com/airspace /media/...pdf/.../aircraft-finance-2013.pdf (2013).

4. Team SAI and back Aviation, Maintenance, Repair and Overhaul (MRO) world market forecast. http://backavaition.com/MRO (2006).

5. Jackman, F., MRO market up modestly as efficiencies take hold. Overhaul \& Maintenance, 12 (4) : 43-50.

6. Lee, S. G., Ma, Y.-S., Timm G. L., Product lifecycle management in aviation maintenance, repair and overhaul. Computers in Industry, 59(2): 296-303 (2008).

7. Alternatives, C. Competitive Alternatives - Highlights, KPMG http://www.compe titivealternatives.com/industries/ CA2012 indprofile aerospace.pdf (2012).

8. Anand, S., Domestic use of unmanned aircraft systems: an evaluation of policy constraints and the role of industry consensus standards. ASTM standardization news, 35(9):30 (2007).

9. Moir, I., \& Seabridge, A., Aircraft systems: mechanical, electrical and avionics subsystems integration (21). Wiley. com. (2008).

10. Kozakiewicz, A., Kowalski, M., Unstable operation of the turbine aircraft engine. Journal of Theoretical and Applied Mechanics, 51(3):719-727 (2013).

11. Rossetti, C. L., Choi, T. Y., Supply management under high goal incongruence: An empirical examination of disintermediation in the aerospace supply chain. Decision Sciences, 39(3): 507-540, (2008).

12. Lombardo D., Study: 2013 World MRO Market Worth \$49.2B, AIN Online. http://www.ainonline.com/aviation-news/ainmxreports/2013-05-15/study-2013-world-mromarket -worth-492b (2013).

13. Michaels, K., Air transport MRO Outlook, implications of high fuel prices. Aerostrategy management consulting. http://www.aviationweek.com/events/html/mro11/MRO $\% 20 \mathrm{US} \% 20-\% 204$. $12 \% 20-\% 20230 \mathrm{pm} \% 20-\% 20 \mathrm{D} 129 \% 20-\% 20$ Michaels $\% 20$ (for $\% 20$ electronic $\% 20$ distribution).pdf (2011).

14. Market research, The Commercial Aircraft Maintenance, Repair and Overhaul (MRO) Market 2012-2022. Market research report. http://www.reportlinker.com/p0591746/Th e-CommercialAircraft-Maintenance-Repair-and-Overhaul-MRO-Market.html (2012).

15. Al-Kaabi, H., Potter, A., Naim, M., An outsourcing decision model for airlines' MRO activities. Journal of Quality in Maintenance Engineering, 13(3) : 217-227 (2007).

16. Dixon, M., The maintenance costs of aging aircraft: Insights from commercial aviation (Vol. 486). RAND Corporation. (2006).

17. Yu, J., Gulliver, S., Tang, Y., Ke, L., New advances in aircraft MRO services: Data mining enhancement. In Advanced Computational Intelligence (IWACI), 2011 Fourth International Workshop on (199-204), (2011)

18. Zhilkin, O. N., Lopatkin, R. V., Aircraft maintenance repair and overhaul market in Russiachallenges and opportunities of the high-tech industry in Russia. Readings book, 1316, (2013). 
19. United States Department of Labor, Aircraft and avionics equipment mechanics and service technicians, http://www.bls.gov/oco/ocos179.htm (2006).

20. Dimitri, V.A.N., Eynard, B., Troussier, N., Belkadi, F., Roucoules, L., Ducellier, G., Integrated Design and PLM Applications in Aeronautics Product Development. In the 19th CIRP Design Conference-Competitive Design (2009).

21. Rashid, M. A., Riaz, Z., Turan, E., Haskilic, V., Sunje, A., Khan, N., Smart factory: E-business perspective of enhanced ERP in aircraft manufacturing industry. In Technology Management for Emerging Technologies (PICMET), 2012 Proceedings of PICMET'12: (pp. 3262-3275). IEEE, (2012)

22. Cantamessa, M., Montagna, F., Neirotti, P., Understanding the organizational impact of PLM systems: evidence from an aerospace company. International Journal of Operations \& Production Management, 32(2): 191-215, (2012).

23. Pritchard, D., \& MacPherson, A., Boeing's diffusion of commercial aircraft design and manufacturing technology to Japan: Surrendering the US aircraft industry for foreign financial support, (2009)

24. Doran, D., Rethinking the supply chain: an automotive perspective. Supply Chain Management: An International Journal, 9(1):102-109, (2004).

25. Aviation Attorneys, Network newsroom, www.avaitionattorneynetwork.com (2006)

26. Tegtmeier, L. A., Training not immune from market, technology forces shaping industry. Overhaul and Maintenance. (2002). 